\title{
Towards a theory of EU sports law and policy
}

Traditionally in Britain, sports law has not been a theorised area of study. To some extent this unsatisfactory state of affairs still persists despite the teaching of sports law as an academic discipline on a growing number of University programmes. Sports law programmes are run by the Anglia Polytechnic University, Kings College, the Manchester Metropolitan University and the University of Westminster. The reporting and analysis of sports law is improving. Since 1993 the British Association for Sport and the Law based at the Manchester Metropolitan University has published the Sport and the Law Journal. Since then a growing number of journals have contributed to the reporting and analysis of sports law. Among the main publications are the Sports Law Bulletin, Sports Law Administration and Practice Journal and the International Sports Law Review. The maturation of sports law as an academic discipline is also reflected in the growing volume of academic texts on the subject. In addition to Grayson's seminal Sport and the Law (1994), recent additions to the sports law catalogue include, Gardiner et al.'s Sports Law (1998, 2001), Beloff et al.'s Sports Law (1999), Caiger and Gardiner's Professional Sport in the European Union: Regulation and Re-regulation (2000), Greenfield and Osbourne's Law and Sport in Contemporary Europe (2000), McArdle's From Boot Money to Bosman: Football, Society and the Law (2000), O'Leary's Drugs and Doping in Sport: Socio-Legal Perspectives (2000) and Greenfield and Osbourne's Regulating Football (2001). Others do exist and more are planned.

The expansion in this interest shown to sports law has undoubtedly served to theoretically strengthen the discipline. Nevertheless, much of the attention on sports law has been written by practitioners with practitioners in mind. Whilst this has underpinned sports law with insightful legal analysis, the academic discipline of sports law remains theoretically fragile. As Gardiner explains, 'what is now needed is increased examination of why law is involved increasingly in sport - a legal theory of sports law' (Gardiner 1997: 12). Furthermore, as Beloff et al. recognise, sports law is 'a field which 
has yet to be subjected to thorough treatment from a theoretical perspective' (Beloff et al. 1999: 15).

The theorised field of sports law is however far from barren. Given the apparent relationship between the commercialisation of the sports sector and juridification, the emerging dominant theoretical approach has concerned regulation (for a review of the literature see Gardiner et al. 2001). Foster's presentation of a typology of different models for regulating sport proves particularly useful when examining EU involvement in sport (Foster 2000b). Foster examines five models of sports regulation. The first is the pure market model in which sport is seen purely as a business, subject to the same type of regulation experienced by other businesses. Although an essentially non-interventionist model, the actors within sport are seen as economically maximising individuals and as such the normal form of regulation is through the market and the predominant legal instrument is regulation. The danger with the free market approach is that sporting competition will be eliminated as the weaker participants struggle to compete with the strong. With the defective market model of regulation, competition law can be employed to ensure monopoly does not result from the market approach. The consumer welfare model addresses other limitations of the pure market model. Regulation can protect the rights of the disadvantaged within sport. Foster notes that historically fans and players have had limited economic power against their clubs. This model gives these groups legislative protection from sporting federations. The natural monopoly model assumes that sport is organised as a natural monopoly and that statutorily backed regulation is required in order to regulate its activities. Due to the existence of monopoly, competition law is viewed as an inappropriate regulatory tool. Finally, Foster identifies the socio-cultural model in which sporting values are considered more important than profit. The social and cultural significance of sport and indeed sports autonomy is protected from commercial pressures. Clearly the commercialisation of sport has implications for the adoption of such a regulatory approach to sport. The maximisation of profit by sports bodies is arguably as important as the protection of the socio-cultural aspects of sport. Foster argues a form of 'supervised self-government' may reconcile these commercial and sporting interests (Foster 2000b: 269).

Foster's typology has implications for the analysis of EU involvement in sport. Lowi's classification of policy types - regulatory, redistributive and distributive policies - has been adapted for use within the EU by Pollack (Pollack 1994). Pollack argues that the EU pursues policy involvement in each of these areas. As Pinder acknowledges, due to the EU's constitutional predisposition for negative integration, the forces of regulation are strong in the EU (Pinder 1993). Furthermore, as the EU lacks a Treaty base to develop a legally rooted common sports policy, it has emerged as a EU competence as a regulatory policy. Nevertheless, as Hix indicates, regulatory policy 
making can involve more than removal of barriers to trade (Hix 1999: 215). Such 'de-regulatory' policy making is often accompanied by 're-regulatory' policy making in which regulation is underpinned with policy values. EU environmental policy is one example of the interplay between regulation and values. As Bell and McGillivray explain,

it is an inescapable fact that environmental law and environmental lawyers do not operate within a value-free vacuum ... environmental law is for the real world, where political, social, scientific and economic factors influence the way that law works in practice. Thus, when environmental rules are placed into a practical context there is a need to be aware that law is not some stand-alone monolith which can be interpreted in isolation from external issues, in particular values. (Bell and McGillivray 2000: 28)

Consequently, it is not uncommon for regulatory policies to become penetrated by political and other values.

Foster poses (and answers) a number of important questions in relation to the regulation of sport. First, why regulate? The commercialisation of sport, the unequal power distribution within sport and the monopolistic structure of sport all point to reasons why sports should be regulated. Second, who is to be regulated - the clubs or the governing bodies? Third, what kind of regulation is preferred? Foster argues that sporting selfregulation can be justified on three grounds. First, sport is best placed to regulate its own activities due to the specialism it has acquired. Second, the cost of regulation is borne by sport itself. It is therefore cheaper. Third, selfregulation is likely to produce better compliance. The case against selfregulation essentially concerns public interest arguments. First, sporting structures are undemocratic and do not evenly distribute power to all stakeholders. Regulation has the potential to address many problems in sport such as excessive commercialisation. Governing bodies have been unwilling or unable to tackle these wider public interest issues. A related concern is the lack of accountability and the absence of good practice in sport. Regulation can impose good governance on sport, a claim which fundamentally challenges the 'sport knows best' argument for self-regulation (Foster 2000b: 270-280).

These arguments are equally as applicable in the context of the EU as they are in national jurisdictions. Traditionally a distinction has been made between regulation and law. In other words, as Foster argues, 'law is seen as adjudicating between different private interests and regulation as protecting the public interest against private self interest' (Foster 2000b: 277). This distinction loses its relevance in the context of the EU. Both competition law and the law of the four freedoms are heavily influenced by both private and public interest concerns. ${ }^{1}$ In the absence of a Treaty base for sport denying the EU the opportunity to pass sports legislation, law has become an essential component of the EU's regulatory policy interest in sport. 
Flowing from Foster's analysis is an additional question relevant to regulation at the EU level. Beyond the questions of why regulate, who is to be regulated and what kind of regulation is preferred is a potentially more problematic question. Why has the regulation of sport changed in the EU? The review of EU activity in sport conducted in Chapter 1 indicates the extent to which the nature of the EU's regulatory approach has changed. A review of pre-1999 case law in the EU locates the EU's regulatory involvement in sport towards the 'market' end of Foster's spectrum - in other words Single Market regulation predominated as the EU employed free movement principles and competition law to correct market failures and distortions. The commercialisation of sport was used to justify this approach. Yet, the EU pursues political policy interests in sport which extend beyond the issue of market regulation. The EU has a political interest in the social and cultural dimensions of sport. The activities of the sociocultural advocacy coalition have been successful in changing the nature of regulation to locate it more towards the 'socio-cultural' end of Foster's regulatory spectrum - socio-cultural regulation. This begs an obvious question. How do regulatory policies change in the EU? The methodology employed to answer this question is applicable for understanding why policies change at all in the EU.

These questions go to the heart of the debate on European integration theory. In the context of this text, the questions are, how has the EU developed a sports policy in the absence of a Treaty Article for sport and what drives sports policy change? Central to these questions is the further issue of why the content of EU sports policy has been dominated by the development of sport law? The short answer is that sports law has emerged as a tactic to enable the EU's competing policy has objectives for sport to co-exist. In the absence of guiding legislation, sports law provides stability and the necessary legal certainty for the EU to continue to pursue a regulatory interest in sport without undermining its socio-cultural policy objectives for sport. It is argued below that policy analysis can be employed as a tool for theoretically strengthening the sports law argument.

The literature on European integration falls, very broadly, into one of two categories. The roots of integration theory lie in the post-war attention paid to the EU as an emerging political state. Political science and international relations theory filled the theoretical void by attempting to understand the motivations for establishing the new political system (the transactionalist/ communications approach) and the aspirations for its development (federalism and functionalism). As the EU evolved, intergovernmentalism and neofunctionalism emerged as the dominant paradigms, explaining both the nature of the organisation and predicting the future of integration. Both approaches focused particularly on the major constitutional decisions to have shaped the EU. However, 'it is important to focus, not simply on the process through which major institutional change takes place in the EU, but 
also on the day to day functioning of the EU as a polity' (Cram 1996). As such, a body of literature drawn from comparative politics and policy analysis has emerged which examines the governance of the EU. Therefore, whilst intergovernmentalism and neo-functionalism attempt to explain the process of integration, approaches drawn from policy analysis focus their attention on the politics of governance.

Sport is not unique in becoming linked to the operation of the Single Market in the absence of a Treaty base. At its inception the EU lacked a cultural, media, education and environmental policy. Today, the EU has extensive involvement in these and other important policy sectors. How does the EU acquire an interest in these areas despite the lack of a Treaty base? What processes are at work that give rise to the development of distinct areas of law such as environmental law? Essentially, what is being examined is 'task expansion'. Pollack offers a definition. 'By task expansion I mean (a) the initial expansion of the Community agenda to include new policy areas and (b) the subsequent development and growth of substantive policies in each of these new policy areas' (Pollack 1994: 96).

This two-stage process has been evident in the development of sport as a EU competence. Initially, general legal principles were applied to sport thus giving sport a EU dimension. The ECJ rulings in Walrave, Donà, Heylens and Bosman stemmed from the general application of law of the four freedoms. Post-Bosman sports case law has taken place within the context of a political debate concerning the substantive development of sport as an area of competence. Evidence indicates that the ECJ and the Competition Directorate are increasingly recognising the specificity of sport in their case law. The shift in the regulatory approach to sport has given rise to a distinct area of jurisprudence known as EU sports law.

The birth of EU sports law has wider implications. As an emerging federation the EU is involving itself in a growing range of policy sectors, some of which are extra-constitutional - they lack a formal Treaty base. This challenges the assumption that the EU is not omni-competent or cannot become omni-competent without huge Treaty reform. Of course the EU may not wish to become omni-competent in its truest sense, but in an environment where consensual decision making over Treaty reform is becoming increasingly laboured (particularly with the prospect of enlargement), now is an opportune time for researchers to (re)examine 'creeping competence' (Pollack 1994, 2000).

It is the contention of this chapter that approaches focusing on the process of integration are ill equipped to deal with the complexities of modern EU governance. The arguments forwarded by intergovernmentalists and neofunctionalists are reviewed in the first section of the chapter. The favoured approach is drawn from the body of literature examining the politics of governance. The second section reviews this literature and establishes the analytical framework of the book. 


\section{The process of integration}

\section{Intergovernmentalism}

For intergovernmentalists, state actors control policy evolution in the EU. Far from diminishing the influence of the nation state, European integration is resisted by the 'obstinate' state (Hoffmann 1964, 1966), strengthens the nation state (Milward 1992) or it depends on inter-state bargains (Moravcsik 1991, 1993).

Hoffmann's obstinate nation state restricted itself to uncontroversial economic integration. Although observable in some sectors, such as welfare, Hoffmann saw the neo-functional concept of spillover as being empirically flawed (see below). Rather than embarking on positive integrative steps, the EU found it easier to follow the negative integration route of removing obstacles to trade. Perversely for Hoffmann, the success of spillover is likely to be its undoing since 'the more each partner has already obtained through past measures - the less he will be incited to make new concessions in anticipation of further gains' (Hoffmann 1965: 85). Furthermore, the more integration progresses from the economic field (low politics) to the political field (bigh politics) the greater the chance of failure. In the realm of high politics nation states were not prepared to be compensated for their losses by gains in other areas. Instead, the nation recoils from these difficult decisions preferring instead the tried and tested nation state approach in which uncertainty is perceived to be minimised. Hoffmann's observations in this connection are supported empirically by two events, the failure of the European Defence Community in 1954 and the Luxembourg Crisis of 1965/1966. In both cases the Community failed to break new ground because integration had tried to break out of the narrow confines of economic integration. For Hoffmann therefore spillover is limited in its applicability and once applied outside its boundaries becomes no more than an act of faith.

Milward's historical intergovernmental account of European integration does not begin with the assumption that European integration has been an altogether modest affair (Milward 1992, Milward et al. 1993). Instead, he asserts that the institutional and constitutional development of the EU was not an attempt to erode the nation state, and as such a move to be resisted, but an attempt at strengthening it. Milward argues that the EU became an external support system for Europe's nations, creating a new political consensus capable of rescuing the nation state but requiring a limited transfer of sovereignty. The policy competencies acquired by the Community reflected the desire by Europe's nations to underpin and stabilise the consensus on which the European nation was rebuilt. The motivation for the post-war rescue of the nation state was therefore economic, but within that framework existed the greatest political barrier to this rescue - the German question. Milward suggests that European integration developed at the 
intersection between these two ambitions. By examining this intersection, Milward explains how national policy became internationalised, a clear acceptance by Europe's nations that the rescue of the nation state could not be achieved within traditional national borders. As such Milward attempts to re-assert the role of the historian within explanations for post-war European integration. In effect, Milward accuses political science and integration theorists as having been unmasked by history. Empirically the work of Deutsch, Haas, Lindberg and Lipgens is flawed because central to their diverse theses is the assumption that the nation state is being superseded by a new form of governance promoted by increased communications (Deutsch), spillover (Haas and Lindberg) or a federally directed change in political consciousness spurred by the war (Lipgens).

Moravcsik's accounts of European integration focus on the preferences and power of the member states. Moravcsik refined his earlier work on intergovernmental institutionalism by adding to his theory of interstate bargaining an explicit theory of national preference formation grounded in liberal theories of international interdependence (Moravcsik 1991, 1993). Moravcsik employs these two theoretical approaches to test his claim that European integration depends on macro-level interstate bargains negotiated by member states with the aim of managing economic interdependence. Moravcsik treats the key intergovernmental players as essentially rational actors seeking to maximise their rationally conceived interests, constrained by domestic societal forces and the international environment. Moravcsik employs a liberal theory of state-society interaction and national preference formation to explain how governments define interests. He then employs an intergovernmental theory of interstate strategic interaction to account for the bargain which takes place between member states in order to realise those interests. The political outcomes of these intergovernmental bargains reflect the preferences and bargaining power of the various member states. Moravcsik sees the supranational institutions as having little influence in shaping these outcomes. Rather, institutions in the EU are used to facilitate intergovernmental bargains and improve decision-making efficiency.

Moravcsik's rejection of neo-functionalism is two-fold. Empirically, neofunctionalism has mis-predicted the course of European integration. The emphasis on functional and political spillover has been misguided. Functional linkages can only sporadically be detected, fundamentally calling into question the gradual and automatic nature of integration. Indeed, events such as the 1965 Luxembourg crisis and resulting compromise of 1966 have demonstrated the resilience of the nation state in the process of integration. Rather than the smooth process outlined by neo-functionalists, European integration has proceeded in fits and starts through intergovernmental bargains that have set the agenda for 'an intervening period of consolidation' (Moravcsik 1993: 475). Similarly, Moravcsik sees the concept of political spillover as flawed. He sees the autonomous influence of supranational 
officials as increasing 'slowly and unevenly, if at all' (Moravcsik 1993: 476). Second, Moravcsik makes a theoretical criticism of neo-functionalism. Rather than employing general theories of international political economy, neo-functionalists attempted to explain European integration as a unique process. As a result, neo-functionalism lost the benefit of comparability and testability.

\section{Neo-functionalism}

From a neo-functional perspective, policy evolution in the EU is functionally determined and supranational actors play a key role in defining policy alternatives. Two strands of neo-functional thought are relevant in this respect functional and political spillover. From Ernst Haas's early neo-functional work in The Uniting of Europe to more contemporary revisions, the concept of functional spillover has been an enduring centrepiece of neo-functional theory (Haas 1957). The content, timing and nature of this functional spillover has been questioned yet it continues to be employed by integration theorists as an intervening variable between functional action and European political integration, a dynamic absent in Mitrany's functionalist account (Mitrany 1943 [1966]). Functional integration is essentially economic in nature. It refers to the build up of pressure created by incomplete integration by modern interdependent economies.

The focus on the economic rationale for integration in the face of mounting international pressures is a strand of neo-functional thought similar in conception to other theoretical accounts of regional integration. Moravcsik, a leading critic of neo-functionalism remarked, 'the focus on economic interests may still be viable. It remains plausible for example, to argue that integration is a distinctive policy response of modern welfare states to rising economic interdependence' (Moravcsik 1993: 476).

Despite the similarity, neo-functionalism remains clearly distinct from the intergovernmentalist camp in that neo-functionalism de-emphasises state capabilities in the regional integration process. Furthermore, the economic rationale for integration as developed by neo-functionalists was seen as merely one dynamic in the integration process, the others being political and societal factors (see political spillover). For the neo-functionalist, the economic decision to integrate one sector creates pressures for further sectoral integration. Only by following this incremental logic can the policy maker ensure the maintenance of the gains achieved by the initial decision to integrate. The decision to harmonise coal and steel policy in Europe in 1952 for example, created pressures for further sectoral integration in functionally linked areas. The realisation of the benefits of the European Coal and Steel Community (ECSC) necessitated a wider, more general level of economic integration as embodied in the 1957 Treaty of Rome. As Haas explained, 'policies made pursuant to an initial task can only be made real if the task itself is expanded, as reflected in the compromises made among the states 
interested in the task' (Haas 1961). From this perspective, incremental task expansion becomes a necessity as a half way house between integration and sovereignty would be unsustainable. Clearly, therefore, neo-functionalists see this as a crucial dynamic, perpetuating task expansion as 'problems in one area will raise problems or require solutions in another' (Muttimer 1989).

In its original form, functional spillover was portrayed as a theoretical breakthrough, a plausible explanatory and predictive account of how European integration would become self-sustaining. In essence functional spillover was regarded as automatic and essentially inevitable, 'sector integration ... begets its own impetus toward extension to the entire economy even in the absence of specific group demands and their attendant ideologies' (Haas 1957: 297). These alleged self-sustaining properties of European integration have however never been universally accepted as representing reality. Even though occasional functional linkages could still be detected, progress has been patchy and far from smooth. By 1961, Haas had called into question his original expectation concerning the inevitability of spillover. Instead he argued, 'functional contexts are autonomous. Integrative forces that flow from one kind of activity do not necessarily infect other activities, even if carried out by the same organisation' (Haas 1961). The experience of the 1965 Luxembourg crisis followed by the retrenchment of the 1970s forced neo-functionalists into even greater retreat. Less than 20 years after commenting on the unsustainability of a 'half-way house' between integration and sovereignty, Haas, in 1976, described the EU as exactly this (Haas 1976).

In addition to functional spillover, neo-functionalists also identified a complementary process, political spillover. 'Political spillover, in short, consists of a convergence of the expectations and interests of national elites in response to the activities of the supranational institutions' (Cram 1997: 16). At the supranational institutional level, political spillover is promoted by the independent, autonomous and essentially creative actions of the European Commission, Parliament and the ECJ. From this perspective, political behaviour and policy outcomes in the EU are shaped endogenously through a process of supranational institutional creativity. The Commission, Parliament and ECJ can detach themselves from tight member state supervision to expand the policy remit of the EU. This might be achieved through the exploitation of institutional powers, the exaggerated interpretation of Community goals, the seizing upon of crises to expand policy, the creative use of brokering or a combination of all of these backed up by considerable personal skill on the part of leading figures. For Haas, this institutional ingredient is central to neo-functional theory: 'the existence of political institutions capable of translating ideologies into law is the cornerstone of the definition' (Haas 1957).

Haas also identified a societal dimension to European integration. Acting as agents of European integration, supranational institutions promote dialogue between the central authority and relevant interest groups. As more 
sectoral areas are brought under supranational control within the regional integration process, so traditionally nationally centred belief systems would change. 'As time went by, these interest groups would come to appreciate the benefits of integration, and thereby transfer their demands, expectations and loyalties from national governments to a new centre, thereby becoming an important force in favour of further integration' (Pollack 1994: 99).

Haas's example of shifting societal expectations was drawn from the experience of the ECSC which was viewed with scepticism by most industrial groups in 1951 yet by 1955 became the focus for demands for more supranational powers. Good experience of integration therefore breeds familiarity, trust and crucially demands for more action. The task of the supranational institutions is to develop channels of communication facilitating this bottom-up demand shift and ultimately translate such demands into legislative (or indeed judicial) action, thus expanding the institutional and policy remit of the Community. The supranational institutions thus provide the home for shifting societal demands.

As with functional spillover, the concept of political spillover has also been re-examined. Haas, drawing on the work of Lindberg and Scheingold (1970, 1971) explained how different integration outcomes are likely. Lindberg and Scheingold identified three such possible outcomes, 'the fulfilment of a postulated task on the part of practices and/or institutions created for integrative purposes, the retraction of such a task (i.e. disintegration) and the extension of such a task into spheres of action not previously anticipated by the actors' (Lindberg and Scheingold 1971).

The 'crisis' of neo-functionalism in the 1970s and early 1980s became replaced by renewed theoretical optimism with the launch of the Single European Market project. Clearly, however, any revised concept of functional and political spillover would have to take into account the role of key actors in shaping political outcomes. In particular, the failing of early neofunctionalism lay in it de-emphasising state actors. As such, although a move towards some kind of supranational political integration could be detected, the process was unpredictable, depending in large part on the calculations of self interest made by the member states. From an internal perspective the relationship between the Single European Act, the Maastricht Treaty and the Amsterdam Treaty can be functionally examined. Externally however the collapse of Communism and the re-unification of Germany point to an equally persuasive set of dynamics. The danger is that spillover becomes a term conceptually stretched over a set of events to which the concept may or may not be applicable. 'Spillover, then, is rather like a mirage; it is there if you want it to be' (O’Neill 1996: 129).

Implications for EU sports law and policy

Largely absent from the analytical foundations of intergovernmentalism and neo-functionalism has been a focus on the role of the ECJ in the integration 
process. This gap in the literature became populated throughout the 1990s (see for instance Burley and Mattli 1993, Volcansek 1992, Weiler 1993, Garrett and Weingast 1993, Wincott 1996; also see Chapter 4 where a more comprehensive review of legal approaches is conducted).

Burley and Mattli's classic neo-functional analysis of the role of the ECJ places heavy emphasis on the cultivation of integration by the Court. The ECJ has constitutionalised the Treaty through a process in which law has spilled over from purely economic sectors to new spheres. Making the observation that the law governing the free movement of workers spilled over into the sphere of sport via Bosman is, on the face of it, appealing. Furthermore, the ECJ's rejection of member state submissions supporting the maintenance of the transfer system appears to further undermine the intergovernmentalist argument on state supremacy.

By contrast, intergovernmentalism rejects the idea of a Court able to engineer integration in a manner inconsistent with member state preferences. The member states power of sanction over the Court has the effect of reigning in the ECJ's judicially active impulses. Occasionally governments may be prepared to accept short-term losses in order to secure wider long-term gains. The 'defeat' in Bosman, can therefore be viewed in this light. In other words, even though the ruling was unpopular within national capitals, it did not fundamentally undermine member state interests. Indeed, by strengthening the principle of the freedom of movement, the ruling was in fact consistent with the member states wider interests.

Given the depth of theoretical and empirical material provided by intergovernmentalism and neo-functionalism, why not employ these tools to examine the birth of EU sports law and policy? Two central reasons have already been discussed above, namely the level (macro in nature) and insularity of the approaches. However, taking each approach in turn, further related weaknesses are evident.

First, intergovernmental analyses of policy evolution overstate the importance of state actors within the EU whilst under-estimating their commitment to achieve 'positive' integration. Clearly, the member states are important to the development of policy in the EU but they do not monopolise the process. The EU is far more multi-layered and complex than intergovernmentalists claim (Marks et al. 1996). As such, an approach is needed that can capture the real nature of EU subsystemic, systemic and supersystemic governance (Peterson 1995). Indeed, when tracing the emergence of a de facto EU sports policy, member state involvement at the Amsterdam Summit represents only the tip of the iceberg and the first formal involvement of the member states. Since Amsterdam, the member states have become more active. If a post-Amsterdam snapshot of sports policy development were to be taken covering the period 1998-2000, an intergovernmental analysis may become more appealing. However, this would be to exclude an analysis of the messy development of sports policy prior to 
member state involvement. Accordingly, an approach is required that not only captures the real nature of EU governance, but also adopts an historical, not snapshot approach. Intergovernmentalism may therefore have some value in accounting for policy 'decision', but it is more limited in terms of explaining 'agenda setting' and 'issue definition' (Hogwood and Gunn 1984). At best, state actors are merely one (albeit powerful) policy advocate within any given policy subsystem.

If intergovernmentalism is of limited applicability, what of neofunctionalism? It has already been noted that Burley and Mattli's neofunctional analysis of legal integration provides potential insights into the birth of EU sports law. Furthermore, Pollack's neo-functional analysis of task expansion in the field of regulatory policies is also useful in forging a link between the operation of the EU's Single Market and the development of new policies. In relation to regulatory policies, Pollack argues that the initial decision to establish a common market set in motion a dynamic process of functional spillover in relation to regulatory policies. He argues, 'the existence, timing and content of Community regulatory policies are explicable primarily in terms of functional spillover from the common market' (Pollack 1994: 118). As Pierson argues, the huge range of closely related policy sectors in which the EU involves itself increases the likelihood of new policy sectors being drawn into the regional integration process as an unintended consequence of activity in related fields (Pierson 1996). Functional spillover can therefore develop out of 'high issue density' (Pierson 1996: 139). The proximity of sport to many of the fundamental economic activities of the EU therefore increases the potential of sport being caught within the scope of the law of the four freedoms. For example, Article 42 (ex 51) relating to the adoption of measures in the field of social security necessary to provide for freedom of movement for workers has provided the basis for functional spillover into education policy. In particular, in the mid 1970s, the Commission launched an action programme aimed at facilitating the movement of migrant workers. This resulted in a Council Directive in July 1977 on the education of children of Community migrant workers.

It may be that neo-functionalism only possesses descriptive qualities. The concepts of functional and political spillover are contestable. The notion that functional spillover is automatic is empirically flawed. Although spillover is a useful tool to describe the linkages between policy sectors, it struggles to account for the dynamics driving the connections. Political spillover is also questionable. Neo-functionalism de-emphasises the important role played by state actors. As demonstrated by the Amsterdam and Nice Declarations on sport, the member states have been influential in establishing a EU sports policy. In this connection, neo-functionalism over-emphasises the autonomy of supranational players. The relationship between the ECJ and the Competition Directorate has been influential in linking sport to the EU's 
legal framework but their role cannot be divorced from the wider political context within which they operate. As such, political spillover, although not totally dismissed, is uneven at best. It is clear that individual litigants have been important in bringing sports-related cases before the ECJ and Competition Directorate, however there is little evidence suggesting that this form of bottom-up litigation has been encouraged by EU officials. Indeed, given the increasing caseload of the under-resourced Competition Directorate, it is unlikely Commission officials would want to increase their caseload further. Rather than characterising bottom-up litigation as political spillover, it can be better characterised as legal opportunism.

What lessons need to be drawn when constructing an analytical toolkit for examining the birth of EU sports law and policy? First, an approach is needed that is best able to capture the real nature of EU governance. The EU is becoming a more flexible and multi-layered organisation than intergovernmentalists and neo-functionalists recognise. As such, policy-shaping and making capabilities are dispersed and not monopolised. In addition, the traditional forums for agreeing policy, such as Council/European Council meetings are becoming less dominant as alternative venues for policy development emerge. An intergovernmental decision to grant a policy Treaty status rarely signals the birth of a new policy. Rather, such a move usually formalises pre-existing developments, even if these developments have taken place outside the context of the Treaty. As such, an analytical toolkit must be able to capture the role of these alternative policy and institutional venues and the role played by key policy advocates within them. If no one actor dominates, how are conflicting approaches to policy managed within the formal and informal institutional structure?

The second feature the analytical toolkit needs to capture is an historical approach to understanding policy change. A snapshot of European integration is unlikely to capture the true nature of policy change. Nor is an approach that attempts to scientifically map out integration likely to capture the differences between different policies. Rather, what is required is a methodology for analysing European integration rather than a grand theory, in particular a methodology that examines policy change over time.

The third feature required is an approach that cuts across the insularity of intergovernmentalism and neo-functionalism. State actors and non-state actors are both central to policy evolution. Analysing interstate bargains must remain central to the methodology but must be properly located within the context of a multi-layered EU. In addition, spillover need not necessarily be discarded, rather spillover needs similarly placing in correct context. Constitutive politics or key events, such as a change in the economic status of a sector, can spark spillover. Spillover may also be generated by high issue density or may be encouraged as policy advocates exploit a growing number of institutional venues. However, the inexorable logic of spillover is rejected. 


\section{The politics of governance}

Given the limitations of the political science approaches reviewed above, the researcher must step outside this toolkit for studying European integration and turn to an approach that examines the governance of the EU. This research agenda is more modest. Rather than explaining the big picture of European integration, studying the governance of the EU illuminates the day-to-day detail of integration. In this connection, researchers usually turn to either an actor-based or an institutions-based approach. The approach adopted in this text attempts to bridge the two whilst acknowledging the useful but limited insights offered by intergovernmentalism and neofunctionalism. As such, to address the need to examine the role of key actors, the study employs the Advocacy Coalition Framework (Sabatier 1988, 1991, 1998). In order to capture the crucial role played by institutions, the study uses new institutionalism (March and Olsen 1984, 1989, Armstrong and Bulmer 1998). Alone, the Advocacy Coalition Framework fails to recognise the importance of political institutions in policy evolution. Hence the need to take an 'institutional turn' (Jessop 1990, 2000). However, alone, new institutionalism fails to capture the nature of competition between rival policy advocates. Taken together, they both add theoretical depth to the important yet largely descriptive findings of multi-level governance (Marks et al. 1996).

\section{Multi-level governance}

An essential starting point for this research agenda is an acceptance that the EU can be characterised as a multi-level organisation. As explained above, macro theories of European integration have traditionally tended to overstate or under-state the role played by intergovernmental and supranational actors. By seeing decisional 'power' as dispersed within the EU's policy process we can explain a growing phenomena in the EU, best described as a 'control deficit'. Given a sharing of competencies in decision making, one set of actors, be they intergovernmental or supranational, find it more difficult to control policy development in the EU. Due to a changing institutional balance of power promoted by recent Treaty changes, policy advocates find themselves able to exploit a growing number of institutional venues to shape policy. However, this fragmentation of policy 'influence' need not necessarily lead to analytical fragmentation. A review of multi-level governance (MLG) provides the starting point to illustrate this argument.

The MLG school of thought provides an alternative account of European integration to that of intergovernmentalism and neo-functionalism. The empirical, if not theoretical, strength of MLG lies in the recognition that member states remain the key actors in the process of European integration but increasingly share policy-making competence across multiple levels of government, including sub-national and supranational. In explaining why 
member states no longer monopolise European level policy making, Marks, Hooghe and Blank make three assumptions (Marks et al. 1996: 346). First, decision making in the EU is shared by actors at different levels rather than being monopolised by the member states. Second, individual member state control is diminished by collective decision making in the European Council and Council of Ministers. Third, political arenas are interconnected rather than nested. As such, the state does not act as a gatekeeper between domestic and supranational politics.

Marks et al. use these assumptions as the basis on which to answer the central intergovernmental criticism of why member states would tolerate a slippage in their control. Two broad responses are supplied. First, multi-level governance assumes that the maintenance of sovereignty is just one goal of many for member states. As such, it is not inconceivable that this goal might be sacrificed for the attainment of other goals such as efficient policy provision. The costs of such an action may be felt by the member state but may be offset by the expected benefits, be they economic or political. In addition, life in an electoral marketplace means that member states may tolerate losses in their control if these losses only manifest themselves in the long run. For politicians, the short-term gains are prized whilst long-term costs are discounted (Marks et al. 1996: 349).

Second, member states may use the EU as a shield to insulate themselves from domestic criticism. Furthermore, a member state may accept a loss of control if that is the price that must be paid in order to control the actions of other member states. The strict regulatory ethos of the Single European Market programme reflects the mistrust between member states. Finally, member states may also accept a loss of control in order to limit future reform attempts once they have left office. This ensures a degree of permanence for their original architecture (Marks et al. 1996: 349-350).

Marks et al. go beyond explaining the logic of shifting decision making to supranational institutions to explain why this would entail a loss of individual and collective member state control. The most obvious constraint on individual member state control is the use of qualified majority voting (QMV) in the Council, even though consensual decision making remains a popular informal institutional device (Marks et al. 1996: 350-352). The ability of member states to control supranational institutions collectively is also constrained. The chief opportunity for member states to assert themselves in the policy-making process comes with the negotiation and signing of new Treaties. Although unanimity is the rule, member states do not start with a clean slate. Collectively, unanimity can act as a barrier to policy and institutional reform and even where agreement is possible the ratification process can act as a constraint. Furthermore, the mapping out of the rules of the game can lead to considerable discretion on the part of the supranational institutions as to how to operationalise these general principles. Day-to-day EU governance is therefore an arena intergovernmentalists tend to ignore. 
One of the reasons for this is that intergovernmentalists assume the principal-agent theory will guarantee that if the agents (supranational institutions) are operationalising Treaty principles in a manner undesired by the principals (member states), then the latter will simply replace or reform the agent (Marks et al. 1996: 352-354).

Marks et al. provide four reasons why the principal-agent theory might not necessarily hold. The first constraint on the ability of the principal to control the agent stems from 'the multiplicity of principals'. The existence of 15 principals with different agendas, constrained by unanimous voting, means altering the agent is not straightforward. Indeed, this scenario can further strengthen the agent due to the nature of the Treaties negotiated under these constraints. Disagreements between principals can lead to ambiguous Treaties that reflect compromise and sensitivity. This allows for a diverse and creative interpretation of the Treaty by the agents, whose delegated task is to operationalise the Treaty principles (Marks et al. 1996: 354).

A second constraint stems from 'informational asymmetries', the privileged access to information supranational institutions enjoy. Being involved extensively in day-to-day EU governance gives the supranational institutions an advantage over intergovernmental actors in terms of expertise and access to information. The European Commission in particular benefits from widescale consultation with interest groups, a process Commission officials attempt to develop and consolidate whenever possible. A superior knowledge of EU processes can allow the supranational institutions to distance themselves from tight member state supervision (Marks et al. 1996: 355).

A third constraint limiting the validity of the principal-agent theory results from the use of 'detailed regulation as a response to mutual mistrust.' In cases where member states cannot trust each other to adhere to the rules, for instance in relation to the granting of state aid, rigid regulation of a highly detailed nature tends to be the response. Under these conditions, the Commission and the ECJ have a particularly crucial role to play in developing and overseeing this regulation. In effect, the member states allow themselves to be locked into a particular institutional and policy design because they mistrust one another (Marks et al. 1996: 355).

A final constraint is the emphasis on 'unintended consequences'. Member state rationality is bounded by time, resources, knowledge, multiple values, precedent and organisational limitations (Hogwood and Gunn 1984: 50). Stripped of the ability to continually scan policy horizons, assessing the likely consequences of individual and collective action, member states are forced to gamble with the possibility of unintended consequences. European integration can develop as a result of unintended consequences, especially if supranational actors seize upon them to develop integration and their own remit. Furthermore, if policy or institutional powers develop as a result of unanticipated consequences, member states may be constrained in their 
ability to limit the impact due to the above reasons. Because of the existence of unanticipated consequences, decision making in the EU tends to be incremental. Although this incrementalism may reflect an increased ability of the member states to learn from previous experience, incrementalism can result in a form of path dependence that insulates supranational actors from member state control (Marks et al. 1996: 355-356).

Marks et al. examine four stages of the EU's policy process - policy initiation, decision making, implementation and adjudication - in order to draw three main conclusions regarding the applicability of multi-level governance. First, the member states share decision-making authority with supranational actors. Second, member states are individually and collectively constrained in EU decision making. Third, sub-national interests are active at the European level as well as in the national arena. At all levels of EU decision making, competence is shared. The Commission has a powerful, although not dominant role in policy initiation. The Council shares decision making with the European Parliament in some cases and is constrained by QMV. The implementation of policy is shared and highly restrictive regulatory policies often restrict member state control. In terms of adjudication, the judicial activism of the ECJ, backed up by the Commission and national courts, questions the validity of the principal-agent theory (Marks et al. 1996: 356-371).

Multi-level governance provides the descriptive context within which policy evolves. Decision making and influencing capabilities are shared by actors across numerous levels resulting in no one set of actors dominating. As such the EU is a paradise for those wishing to influence policy. As Peters argues,

agenda setting in the EU is significantly different from that process as it is practised in most national political systems. In particular ... the existence of a number of points of access, of a large number of influential policy advocates, and of a wide range of policy options that have been legitimised in one or more of the constituent political systems makes agenda setting substantially easier than in most other environments. (Peters 1996: 62)

Agenda setting, issue definition and agenda expansion

Pollack's definition of task expansion as '(a) the initial expansion of the Community agenda to include new policy areas and (b) the subsequent development and growth of substantive policies in each of these new policy areas' (Pollack 1994: 96) implies new policies in the EU emerge as a result of a two-stage process. First, an issue emerges on to the agenda (agenda setting) then it is subsequently defined and developed (issue definition). For the purposes of this work the 'agenda' is taken to mean the list of subjects the EU is capable of pursuing an interest in. It refers to a set of issues or problems to which EU officials may have paid some attention, but no policy or set of policies has yet emerged (Kingdon 1995: 3). The term issue definition is taken to mean, 
the process by which an issue (problem, opportunity, or trend), having been recognised as such and placed on the public policy agenda, is perceived by various interested parties; further explored, articulated and possibly quantified; and in some but not all cases, given an authoritative or at least provisionally acceptable definition in terms of its likely causes, components, and consequences. (Hogwood and Gunn 1984)

The definition of an issue also implies some action. Usually, this will be in the form of a policy decision. By distinguishing the systemic agenda from the institutional agenda, Cobb and Elder have made an important contribution to the task expansion debate (Cobb and Elder 1972). The systemic agenda is composed of 'all issues that are commonly perceived by members of the political community as meriting public attention and involving matters within the legitimate jurisdiction of existing governmental authority' (Cobb and Elder 1972: 85). By contrast, the institutional agenda is 'that set of items explicitly up for the active consideration of authoritative decision makers' (Cobb and Elder 1972: 86). A clear similarity exists between the notion of the systemic agenda and the agenda setting stage of the EU's policy process and between the institutional agenda and the issue definition stage.

Accordingly, task expansion refers to (1) the movement of an issue on to the EU's systemic agenda and (2) the movement of the issue from the systemic agenda on to the institutional agenda for definition and development. From a pluralist perspective, agenda setting and issue definition can be explained in terms of open competition between interested groups. Functionalist accounts of the political system devised by writers such as Easton, and Almond and Powell, tended to stress how inputs were converted into outputs in the political 'system' in a rational, non-discriminatory manner (Easton 1965, Almond and Powell 1988). In his New Haven survey, Dahl found no evidence of a ruling elite (Dahl 1961). Indeed observing New Haven, Polsby concluded that, 'in each issue area different actors appeared, their roles were different and the kinds of alternatives which they had to chose among were different' (Polsby 1993: 15). The 'openness and neutrality' (Parsons 1995: 125) of agenda setting from this pluralist perspective has more recently been called into question by writers observing how access to the political agenda is controlled.

An early and influential critic of the pluralist perspective was provided by E. E Schattschneider in the Semi-Sovereign People (Schattschneider 1960). Schattschneider examined how conflict can escalate beyond the original confines of the dispute leaving those originally involved with little or no influence over unfolding events. Agendas therefore have the potential for expansion, yet crucially, for Schattschneider, agendas are controlled and structured by those players (pressure groups, parties or institutions) best able to control this expansion. Whilst the weaker groups seek to expand conflict by recruiting new participants to its support, the stronger side will 
normally seek to suppress conflict. Whereas the 'strong' may seek to restrict participation by adopting narrow technical or procedural definitions of alternatives, the 'weak' may try and link issues to major themes. Accordingly, the same issue may either be 'routine and procedural' or it may 'go to the heart of democracy'.

Schattschneider's work highlights the distinction between agenda setting and issue definition (alternatives). For Schattschneider, 'the definition of alternatives is the supreme instrument of power', and 'he who determines what politics is about runs the country, because the definition of alternatives is the choice of conflicts' (Schattschneider 1960: 69). Indeed, once an issue is on an agenda, the way it is subsequently defined may escalate the conflict. As Rochefort and Cobb explain, 'the outside audience does not enter the fray randomly or in equal proportion for the competing sides. Rather, the uninterested become engaged in response to the way participants portray their struggle' (Rochefort and Cobb 1994: 5). Although Schattschneider's work focuses on how issues are controlled in the policy process whereas this work examines the openness of EU public policy, his focus on conflict expansion is particularly useful. Schattschneider argued that the 'losers' in the policy process would adopt strategies to topple the 'winners'. Such strategies would involve appealing to those currently not involved in the debate. In such circumstances, Sabatier argued that 'losers' would construct 'coalitions of convenience' (Sabatier 1998: 119). Schattschneider's focus on conflict expansion is broadly accepted in this study, although the nature of this is expansion is queried. Within more open, 'multi-level' political systems the researcher must examine the role multiple institutional venues play in the strategies of those wishing to escalate the agenda. Before this can examined an examination of the nature of the agenda is first required.

\section{Systemic agenda setting}

Before an issue is considered on the institutional agenda, it first must have been on the systemic agenda. How does an issue expand to such an extent where governmental action is seen as necessary? For Hogwood and Gunn an issue, especially a new one, will be more likely to reach the systemic agenda if one or more of the following circumstances apply. First, the issue has reached crisis proportions and can no longer be ignored. Second, the issue has reached particularity (for example acid rain). Third, the issue has an emotive or human-interest angle that attracts media attention. Fourth, the issue seems likely to have a wide impact (for example health scares). Fifth, the issue raises questions about power and legitimacy in society. Finally, the issue is fashionable in some way which is difficult to explain but easy to recognise (for example inner-city crime) (Hogwood and Gunn 1984). However, these factors do not guarantee access to the public policy agenda. In order to explain this, Hogwood and Gunn argue that the actions of key players need examining. In particular these include, the agenda setters (organised 
interests, protest groups, party leaders, influentials) and the gatekeepers of the mass media such as newspaper editors and television producers.

Cobb and Elder identify numerous reasons accounting for why an issue may reach a political system's systemic agenda (Cobb and Elder 1972). First, an issue may be well defined. Second, it may possess social significance. Third, it may have a long-term relevance. Fourth, it may be relatively non-technical. Finally, the issue may lack a clear precedent. Like Schattschneider, Cobb and Elder argue that agendas are structured by certain players. Strategies for controlling issue expansion include group strategies and issue strategies. Group strategies may involve the discrediting or co-option of leaders, whilst issue strategies may involve the use of symbols. If a conflict is made sufficiently prominent (most likely with the assistance of the media), access to the formal institutional decision-making process will be facilitated (Richardson and Jordan 1979: Chapter 4). For both Schattschneider and Cobb and Elder, agenda setting is therefore concerned with how conflict is managed, more specifically how conflict is either suppressed or expanded.

Hogwood and Gunn's approach implies systemic agenda setting is externally determined. In other words social, economic and political forces external to the political system compel governments to act. Without rejecting the significance of such forces, is it possible also to identify a set of internal dynamics shaping systemic agenda setting? Paul Pierson's study of the evolution of EU social policy makes an important implicit contribution to the study of systemic agenda setting (Pierson 1996). Employing an historical institutionalist analysis (although in places resembling a more rational choice strand in institutional thought) Pierson examines how unanticipated consequences and high-issue density in the EU may result in the emergence of new issues. Pierson notes that growing issue density has two consequences. First, it generates 'overload' (Pierson 1996: 137). Overload greatly complicates EU decision making for the member states. In such circumstances, member states are more likely to delegate responsibility to supranational actors. Member state 'grip' over an issue may therefore slip. Second, issue density promotes spillover. Due to the huge range of policy issues in which the EU pursues an interest, new policy issues may be unintentionally drawn into the regional integration process, thus giving that issue a EU dimension. Externally generated factors may increase the potential for this to occur. For instance a change in the 'image' of the issue may serve to give it a EU dimension.

\section{Institutional agenda setting}

External and internal forces may pull an issue on to the systemic agenda. The interplay between these two forces may also prove influential in moving the issue on to the EU's institutional agenda for active definition and policy decision. For example high-issue density in the EU may create a 'latent' regula- 
tory environment for a particular industry operating within the Single Market. The regulatory environment may be latent due to the underdeveloped economic status of that industry. In such circumstances the issue will remain on the systemic agenda. However, an externally generated change in the economic status of the industry may activate regulatory interest from the EU. Accordingly, the issue is dragged on to the institutional agenda in a particular form. Pinder argues that in the EU the 'free trade ideology is firmly built into the system, but the planning ethic is no more than a possibility for the future' (Pinder 1968: 98). Although undoubtedly the balance has shifted, the force of the four fundamental freedoms remains strong. The movement of an issue from the systemic to institutional agenda will often therefore be promoted by the logic of negative integration (Pinder 1968). New policy issues are therefore frequently introduced on to the EU's institutional agenda with definition bias. For example legal/regulatory norms held together the sports policy subsystem.

The manner in which an issue reaches the institutional agenda is significant for policy definition and for eventual policy outcomes. It is no great insight into EU policy making to observe that individuals and groups 'frame' issues differently. Those who were instrumental in an issue reaching the agenda may feel their definition is most appropriate. Others may be drawn into the policy process at the issue definition stage in protest at the original definition. As Rochefort and Cobb suggest, 'the uninterested become engaged in response to the way participants portray their struggle' (Rochefort and Cobb 1994: 5). As the post-Maastricht EU has attempted to develop a more social and cultural dimension within the spirit of Adonnino (see Chapter 1), so subsystems dominated by legal and technocratic norms and values are becoming penetrated by broader political arguments. The politicisation of law and regulation has occurred in a wide range of policy subsystems including the single currency, tax policy and media ownership policy (Radaelli 1999a). The sports policy subsystem has witnessed similar politicisation. Issue definition is therefore greatly influenced by value judgements, but with value judgements comes conflict. However, rather than being an obstacle to policy evolution in the institutional agenda-setting stage, conflict can represent an important resource (Harcourt 1998). In this connection, Sabatier's work on competition between policy advocates within policy subsystems is important.

\section{An actor-based analysis: the advocacy coalition framework}

For those wishing to explain policy evolution/agenda escalation in the EU, Sabatier's Advocacy Coalition Framework (ACF) provides an excellent starting point (Sabatier 1988, 1991, 1998). Sabatier's focus on the dynamics of non-incremental policy change has important implications for those seeking to explain a similar phenomena-task expansion. Although not applied to the EU, the ACF's focus on competing advocacy coalitions 
within policy subsystems effectively captures the real nature of EU governance. Sabatier begins his analysis of policy change by examining the growth of public policy (air pollution) environmental programmes in the United States (Sabatier 1988). Sabatier notes that, in the 1950s federal programmes were very limited, yet only a decade later federal expenditures had risen more than 20-fold and by 1970 Washington had instituted a massive regulatory programme designed to improve air quality. Despite this clamour, progress in combating air pollution in the 1970s was slow as other issues such as energy prices emerged and as the technical and political difficulties of action became known. Sabatier's approach to understanding such change is based on three basic premises. First, that in order to fully understand the process of policy change a period of at least ten years should be examined. Second, throughout this period a focus on 'policy subsystems' can help explain policy change. Third, public policies or programmes can be conceptualised in the same manner as belief systems, i.e. as sets of value priorities and causal assumptions about how to realise them (Sabatier 1988: 131).

First, on time span, Sabatier argues that policy change is the result of cumulative effects. For example, as new findings and ideas are fed into the policy process, so policy gradually changes. Indeed it often takes considerable time to implement and evaluate policy once agreed. In short, 'policy analysis has a long-term 'enlightenment' function. Policy analysis gradually alters the arguments surrounding policy problems' (Parsons 1995: 195).

On the second premise, Sabatier views the policy process as comprising more than the 'iron triangle' of administrative agencies, legislative committees and interest groups at a single level of government policy (Sabatier 1988: 131). For Sabatier, the 'policy subsystem' will involve many more actors at various levels of government such as interest groups, bureaucrats, academics, politicians, think tanks and journalists. These actors generate and exchange ideas in relation to policy problems. Subsystems tend to be autonomous due to their specialised nature yet they may involve a large number of actors who are involved in dealing with a problem. For example, Sabatier identifies ten sets of actors involved in the US air pollution control subsystem. These include the governmental bodies, consumer groups, environmental groups, manufacturers groups, academics and researchers and journalists. In the case of acid rain, other countries become involved in the subsystem. These groups are termed 'advocacy coalitions'.

Finally, on belief systems, Sabatier argues that within subsystems lie 'value priorities, perceptions of important causal relationships, perceptions of world states, perceptions of the efficacy of policy instruments' (Sabatier 1988: 132). Given that individuals attempt to translate their beliefs into public policy, it becomes clear that beliefs can play an important role in structuring politics. Beliefs are also important because actors are attracted to one another on the basis of shared beliefs. As Sabatier explains, 
actors can be aggregated into a number of advocacy coalitions composed of people from various organisations who share a set of normative and causal beliefs and who often act in concert. At any particular point in time, each coalition adopts a strategy(s) envisaging one or more institutional innovations which it feels will further its objectives. (Sabatier 1988: 133)

Therefore, for Sabatier, operating within an organisation such as the EU are numerous policy subsystems. A subsystem consists of various actors who are seeking to influence policy. Operating within policy subsystems are competing advocacy coalitions, each composed of a group of like-minded individuals seeking to re-direct policy in line with their particular belief system. Beliefs within an advocacy coalition are organised hierarchically. At the highest level, fundamental ideological beliefs form the deep core. At the next level, policy core beliefs comprise fundamental policy positions and strategies for attaining core values. Sabatier describes policy core beliefs as the 'fundamental glue' of coalitions (Sabatier 1998: 103). At the base of the hierarchy lie a range of narrower concerns such as implementing decisions and policy preferences known as the secondary aspects of a coalition's belief system. Changes in beliefs are more likely to occur in the secondary aspects of a belief system. The empirical although not normative elements of the belief system within the policy core are subject to change through learning over a period of time, whilst beliefs in the policy core remain resistant to change.

Advocacy coalitions attempt to translate their beliefs into public policy through the use of guidance instruments such as changes in rules, budgets, personnel or information (Sabatier 1998: 104). Policy brokers attempt to mediate between conflicting coalitions within a policy subsystem. Policy outputs result from this interaction between competing advocacy coalitions. However, for Sabatier policy making within subsystems is affected by external factors and the internal structure of policy subsystems. Sabatier's approach for examining external factors affecting policy change within subsystems distinguishes between (1) parameters that are relatively stable over decades and (2) those aspects of the system that are susceptible to significant fluctuations over the course of a few years and thus serve as major stimuli to policy change (Sabatier 1988: 143).

The relatively stable parameters (both internal and external to policy subsystem) include:

- Basic attributes of the problem area (or 'good'): Institutional policy options are affected by the issue under consideration. Some issues lend themselves to governmental regulation whilst others can be left to the market.

- Basic distribution of natural resources: A focus on this can help us explain why during the 1970s the USA could encourage utilities to switch from oil to coal whilst the coal-deprived French turned to nuclear power. 
- Fundamental cultural values and social structure: It is apparent that due to prevailing cultural values and norms that some policy options are not feasible at a given time. Similarly the social structures structure access to politics. Change in these areas is likely to take considerable time.

- Basic legal structure: The constitutional structure of a political system affects both policy change and policy-oriented learning (see below). Basic legal norms tend to be resistant to change thus minimising policy change in this area. Policy-oriented learning can be affected if the policy style of a system is closed preventing learning from taking place.

The dynamic (system) events (external to policy subsystem) include:

- Changes in socio-economic conditions and technology: Public opinion can affect policy change as it did with environmental policy in the 1970s. Major events also have a profound impact on policy. Sabatier notes that the Arab oil boycott of 1973-1974 contributed to calls for a relaxation of car pollution controls, even from groups previously supportive of such efforts.

- Changes in systemic governing coalitions: It is clear that with changes of government come changes in policy approaches.

- Policy decisions and impacts from other subsystems: Sabatier notes that policy subsystems are only partially autonomous. The argument advanced here echoes the logic of functional integration. Sectors cannot be integrated in sectoral isolation. Coal and steel production, for example, cannot be isolated from energy policy, which cannot be isolated from transport policy and so on.

For Sabatier, the internal structure of a policy subsystem is particularly important. This is why Sabatier extended the definition of a subsystem to include journalists, analysts, researchers and other important players. Sabatier makes five observations relating to the internal structure of policy subsystems. First, although members of policy subsystems may be easily identified, it is also important to identify the 'latent' constituency. If this constituency can be activated and brought into the subsystem, this may have a significant effect on policy change.

Second, new policy subsystems are capable of emerging, particularly if actors are dissatisfied at either the way the issue is being defined or by the neglect of an issue. Sabatier notes that in the USA a food safety subsystem emerged from the agriculture subsystem due to the laissez-faire approach to food safety within it.

Third, subsystems usually contain a large number of diverse actors. Methodologically, Sabatier notes that some way of categorising different interests is required. Sabatier points out that within the US air pollution subsystem in the 1970s two sets of advocacy coalitions could be identified, the 'Clean Air Coalition' and the 'Economic Feasibility Coalition' (Sabatier 
1988: 140-141). Advocacy coalitions may be diverse but they do share a particular belief system. For instance, the Clean Air Coalition shared a belief (amongst others) in the primacy of human health over economic development. The Economic Feasibility Coalition believed that a balance between the two should be struck. These shared beliefs 'glue' subsystems together. Usually within a policy subsystem, only between two and four advocacy coalitions exist. This is because in order to gain prominence, coalitions need to be made. Fewer coalitions may be expected to survive as a subsystem matures and coalitions are formed. Some actors may not be aligned to an advocacy coalition. These may include actors such as academics who may be able to offer some expertise or actors known as 'policy brokers'. 'Policy brokers' attempt to find compromises between the positions advocated by coalitions. These brokers may be civil servants, elected officials or courts. Policy brokers are not necessarily neutral.

Fourth, the key objective of an advocacy coalition is to translate their beliefs into public policy. Clearly advocacy coalitions seek to steer policy in a direction compatible with their belief system. However, having a belief system does not guarantee influence. The ability of an advocacy coalition to influence policy depends on resources. Such resources include money, expertise, number of supporters and legal authority.

Fifth, belief systems within advocacy coalitions are hierarchical. Fundamental norms and beliefs form the deep core. Within the policy core are found fundamental policy positions and strategies for attaining core values. Finally, instrumental decisions and information searches necessary to implement the policy core, forms the secondary aspects. Change is more likely to occur in the secondary aspects than it is in the policy core or in the deep core. Changes at the level of the policy core are due to factors such as changes in macro-economic conditions, changes in fundamental cultural values and social structure or new systemic governing coalitions. Change takes place at the secondary level as a result of 'policy-oriented learning' between advocacy coalitions. Policy-oriented learning is a form of learning which leads actors to make alterations to their thought patterns or behavioural intentions as a result of past experience. Sabatier argues that, 'policyoriented learning across belief systems is most likely when there exists a forum which is (a) prestigious enough to force professionals from different coalitions to participate and (b) dominated by professional norms' (Sabatier 1988: 156).

Richardson sees this trend as emerging in the EU. For example the EU has a history of establishing forums, such as the environmental or consumer forum to bring together a wide spectrum of interests to discuss policy evolution (Richardson 1996: 18). This has also been the case with sport. The European Commission has established dialogue with European sporting interests through the establishment of the European Sports Forum. In addition a European Conference on Sport, organised by the Commission, was held 
in Greece in May 1999. Such occasions are designed to force debate among professionals in an attempt to achieve some convergence of views regarding the nature of the problem and thus the content of the policy solution.

In summary, Sabatier identifies a number of factors affecting the development of policy within a subsystem. First, policy subsystems are affected by significant perturbations external to the subsystem. Sabatier identifies two such forces, both of which provide constraints and opportunities for subsystem actors. On the one hand, 'relatively stable' factors such as the basic constitutional structure, socio-cultural values and natural resources of a political system are unlikely to radically change even in the face of coalition strategies (Sabatier 1998: 102). Similarly, 'external events' such as major changes in socio-economic conditions, changes in public opinion, changes in the systemic governing coalition and policy decisions and impacts from other subsystems are likely to significantly affect policy subsystems. Although significant, Sabatier views such external forces as insufficient to cause changes in the policy core attributes of a governmental programme.

Second, external 'perturbations' provide opportunities for policy entrepreneurs to exploit. Such entrepreneurs wish to change policy in some way.

Third, policy change may stem from competition between coalitions. Although external perturbations may result in conditions which lead to the replacement of one dominant coalition by another, a more likely scenario is that a minority coalition increases in importance to such an extent that it can exploit a window of opportunity to challenge the dominant coalition. Usually, the minority coalition lacks the (legislative) resources to push for the adoption of its policy objectives. Under such circumstances the coalition will develop coalitions of convenience with other groups (Sabatier 1998: 119).

Fourth, compromise rather than conflict may lead to policy change. Sabatier notes that 'in situations in which all major coalitions view a continuation of the current situation as unacceptable, they may be willing to enter negotiations in the hope of finding a compromise that is viewed by everyone as superior to the status quo' (Sabatier 1998: 119). Under such circumstances a power-sharing arrangement will be established.

Fifth, the ACF contends that policy change can also result from a learning process described as policy-oriented learning. This learning process across belief systems is likely to be facilitated by the establishment of a professional forum (Sabatier 1998: 106).

The ACF is not the only actor-based approach able to capture the role played by key policy advocates within the process of policy change. Kingdon uses the concept of a 'stream' to explain the processes involved in agenda setting. Occasionally, the streams align to allow a 'policy window' to open. Policy change takes place within this window (Kingdon 1995). Alternatively, other researchers have employed network analysis to explain policy change (Rhodes 1988). A policy network implies a symbiotic relationship between an interest group(s) and the public policy maker(s). A network is the arena 
for mediation and bargaining between the two. Networks are policy specific. Policy networks are a useful tool for understanding issue definition in the $\mathrm{EU}$, particularly if we distinguish between policy communities and issue networks. Policy communities tend to have a stable membership, are highly insular and have strong resource dependencies. An issue network by contrast has fluid membership, is highly permeable and possesses weak dependencies (Rhodes 1988, Peterson 1995). Within the context of the EU several policy networks may be in operation, some resembling policy communities, others issue networks. A related realm to that of policy networks is the idea of epistemic communities. Such communities are essentially knowledge based (actual or perceived) and are comprised of experts. Being thus composed, epistemic communities are highly influential and seen as legitimate.

Kingdon's main contribution is his focus on the power of ideas and on how solutions 'search' for problems rather than on pressure and influence. Hence given certain propitious conditions, solutions within an organisation are joined to problems. The opening of a policy window increases the likelihood that the 'solution' will be adopted. Although appealing, Kingdon's work suffers from two flaws. First, he puts 'too much distance between the policy and the political stream' (Sabatier 1991: 151). He therefore deemphasises the crucial role played by competing policy advocates and as such his work lacks an advocacy analysis. Sabatier's ACF is an attempt to view Kingdon's 'streams' as more closely related. Second, Kingdon's work lacks an institutional analysis. Kingdon does note that 'institutions, constitutions, procedures, governmental structures, and government officials themselves affect the political, social, and economic system as much as the other way around' (Kingdon 1995: 229). Furthermore, Kingdon notes that 'federalism also enhances possibilities for innovation - if a new idea isn't possible in one venue, it might be possible in another, and entrepreneurs can shop around for the most favourable venue' (Kingdon 1995: 230). Kingdon is correct in his analysis, even though his brand of institutionalism merely examines the constraints institutions place on individuals. However, like Sabatier who also briefly notes the importance of institutions, it is not clear why Kingdon does not explicitly attach an institutional analysis to his actorbased analysis of policy change.

Policy networks and epistemic communities are useful for analysing policy change in the EU as they act as a mechanism to order and describe the range of actors involved in the policy process and describe the relationship between them. However, Sabatier's ACF performs this function even better. Furthermore, policy networks suffer from a number of flaws. Network analysis places too much emphasis on pressure and influence within the policy process and not enough on the power of ideas and belief systems. Sabatier's work addresses this. Furthermore, are policy subsystems characterised by stable and symbiotic relationships between policy makers and advocates, a particular feature of the policy communities approach? Even the looser 
conception of issue networks and epistemic communities fail to capture the true nature of competition between advocates of which decision makers form a part. Finally, network analyses pay insufficient attention to the exploitation of institutional venues for the 'outsider'/'losing' advocacy coalitions. Network analysis may prove useful for accounting for the reconciliation/mediation that often takes place between rival coalitions, but even here network analysis lacks an important institutional dimension.

There is in effect much similarity between the actor-based approaches reviewed above. Although the language differs they all seek to move away from an old institutional analysis and relocate their analysis on the individual. Sabatier's framework is preferred because it best captures the real nature of competition between rival advocacy coalitions operating within the context of policy subsystems, a particularly pronounced feature of EU governance.

Despite the strength of Sabatier's work, the ACF is not without its critics. The key criticism is that the ACF pays insufficient attention to the problem of collective action. Schlager notes that although the ACF (and indeed work on policy communities and policy networks) has shed considerable light on the dynamics of policy change, it has tended to ignore this problem of collective action (Schlager 1995). The ACF has proved useful in explaining the structure of coalitions, the importance of coalition competition in sparking policy change and the role of policy-oriented learning, yet it does not explain 'why actors holding similar beliefs form coalitions to collectively press their goals, how coalitions maintain themselves over time, or the strategies coalitions adopt to pursue policy goals' (Schlager 1995: 244). Furthermore, Olson questions why actors with shared interests will act together when a 'rational' course of action would be to free-ride on the back of the actions of others who would bear the cost of action (Olson 1971). However, this may prove an unanswerable question given that all action, even those determined by particular incentives, involves the payment of some costs from which others will benefit (Marwell and Oliver 1993). Olson's other contention - that successful collective action is more likely where small groups will be strongly motivated to act - may however have relevance to the EU and have implications for explaining the dynamics of coalition action (Peterson and Bomberg 1999: 27).

For the ACF to assume increased relevance to the EU, the issue of coalition strategies must be addressed. The multi-level institutional structure of the EU described above has profound implications for actor strategy. The ACF is strong on providing 'external' reasons for policy change within a subsystem but considerably weaker on integrating the activities of advocacy coalitions into the explanation of policy change. In other words, 'for coalitions to take their rightful place in the policy process requires an explanation of action' (Schlager 1995: 248). The actor selectivity inherent in institutional design is crucial to this action. 
An institutional analysis: belief systems and political institutions

How can the crucial issue of coalition action be addressed? As Schlager notes, 'if the ACF is to better account for action, the institutional structure and characteristics of the situation in which coalitions form and act need to be better specified. The institutional setting which both constrains and promotes action must be further developed' (Schlager 1995: 259).

In essence therefore Sabatier's work, like other actor-based approaches, lacks an institutional analysis. The correct deployment of such an analysis can provide that crucial missing ingredient in Sabatier's work: the explanation of action. Sabatier notes that the ACF's 'ability to deal with complex situations and its model of the individual derived from psychology make it attractive to scholars looking for an alternative to the institutional rational choice models currently dominating much of policy scholarship' (Sabatier 1998: 122).

However, Sabatier also notes that actors are driven by a more complex set of factors than rational calculations of self-interest. In particular, he claims that 'actors suffer from a variety of cognitive biases and constraints' (Sabatier 1998: 109). First, in the face of time and psychological constraints, actors resort to 'satisficing' (Hogwood and Gunn 1984: 50) or guideline behaviour consistent with their general belief system, particularly in the policy core. Furthermore, 'actors' perceptions are strongly filtered by their pre-existing normative and other beliefs' (Sabatier 1998: 109). Although Sabatier notes that 'financial resources and institutional rules are critical' (Sabatier 1998: 117), the ACF does not attempt to fully examine the relationship between satisficing behaviour, pre-existing beliefs and institutions. Through a closer examination of the influence exerted by political institutions on policy subsystems it is possible to identify institutions as not only constraining subsystems but also structuring belief systems, strategies and policy outputs within them. Without an institutional analysis of policy change and development it becomes tempting merely to emphasise how the political agenda is 'pushed and pulled' around by societal, economic or political forces (Kingdon 1995: 229). Implicit in this approach is an assumption that political institutions are merely neutral arenas in which these forces are played out. However, as Baumgartner and Jones remind us, policy advocates seek to influence agenda setting and issue definition within 'institutional venues' (Baumgartner and Jones 1991: 1045). Institutional venues may affect social, economic and political forces as much as these forces affect institutional venues. Kingdon notes that examples of both state autonomy and the state as a reflection of society can be found in cases of agenda setting (Kingdon 1995: 230). Sabatier's actor-based framework should not therefore be seen as an alternative to institutional analyses, but as complimentary.

The benefits of actor-based institutionalism are increasingly being recognised within political science. In The Games Real Actors Play, Scharpf develops an explicit brand of actor-centred institutionalism in which institutions 
are portrayed as creating opportunity structures and constraints for purposeful and resourceful actors to navigate within (Scharpf 1997). Similarly, Kiser and Ostrom claim that individual action in the policy process is a function of both the attributes (values and resources) of the individual and the attributes of the decision situation of which the prevailing institutional make-up is central (Kiser and Ostrom 1982). Moe's structural choice approach examines the effect political institutions have on the choices coalition's make in their attempts to re-direct public policy (Moe 1990). Schlager seeks to integrate both the institutional analysis and development framework and the structural choice approach into Sabatier's ACF in order to address the issue of coalition formation and action (Schlager 1995). Furthermore, Fenger and Klok seek to strengthen further Schlager's contribution to the ACF by examining the interdependencies between actors (Fenger and Klok 2001). Additionally, Mintrom and Vergari suggest in the policy entrepreneurs model that policy changes as a result of the actions of policy entrepreneurs who do not treat institutional configurations as fixed but as malleable (Mintrom and Vergari 1996).

In the context of the EU, Pollack similarly recognises the importance of institutional configurations. He argues that member states created EU institutions for particular self-serving reasons and allowed for certain procedural mechanisms such as QMV and decision-making delegation to supranational actors in order to facilitate progress towards their rationally conceived preferences (Pollack 1996). However, reform of institutions, once created, may be difficult to achieve by the member states. First, member states may regard the uncertainty of reform and the transaction costs associated with reform as being an unacceptably high price to pay. Second, the institutions themselves may be resistant to reform and may be shielded by institutional procedures such as unanimity requirements. Although reform is not impossible, Pollack suggests it is infrequent, leading to a state of 'punctuated equilibrium', long periods of stability followed by infrequent (Treaty) change (Pollack 1996: 438). When change (integrative or disintegrative) is negotiated, it is likely to be infrequent and, due to the constraints previously described, unlikely to be major. A path-dependent process of integration is likely to result because change will be greatly affected by existing institutions and institutional decision-making rules.

In effect Pollack is describing a process whereby institutions and policies become locked-in. Pollack identifies two brands of lock-in. The first has been developed by Scharpf who identified two conditions, intergovernmentalism combined with unanimity that result in the 'joint decision trap', a condition resulting in institutions and policies becoming entrenched despite pressures for reform (Scharpf 1988). For the second lock-in, Pollack dips into Pierson's historical institutionalist account of micro-level lock-ins (Pierson 1996) (see below). Thus institutions and policies can become locked-in from above (Scharpf) and from above and below (Pierson). 
The work of Baumgartner and Jones also has implications for the ACF (Baumgartner and Jones 1991). Their work is important because their methodology also asserts the importance of examining both actors and institutions. Baumgartner and Jones analyse how public policy often evolves through long periods of stability, punctuated by short bursts of rapid change. Rather than applying different analytical tools to explain the continuity and change of public policy, Baumgartner and Jones retain analytical cohesion by arguing that a single process can explain both periods of extreme change and short bursts of rapid change (Baumgartner and Jones 1991: 1044-1045). Baumgartner and Jones argue that this single process comprises the policy image and the institutional venues of policy action. The policy image describes the 'interaction of beliefs and values concerning a particular policy' whilst the institutional venues refers to the 'venues of policy action' (Baumgartner and Jones 1991: 1045). The choice of institutional venue is clearly important for with it inevitably comes the ability to shape policy in a direction compatible with an advocate's belief system. However, even though an issue may emerge on the public policy agenda with definition bias, alternative institutional venues often exist 'that can serve as avenues of appeal for the disaffected' (Baumgartner and Jones 1991: 1045). This focus adds clarity to actor-based approaches that seek to explain agenda expansion. As Baumgartner and Jones stress, 'as venues change, images may change as well; as the image of a policy changes, venue changes become more likely' (Baumgartner and Jones 1991: 1047).

Although Baumgartner and Jones do not examine the policy process of the EU, their methodology is applicable for studying EU policy evolution. Within the context of the EU it is important to examine the influence of key actors, be they intergovernmental or supranational players. Yet to complete the investigation into agenda setting and issue definition, it is also necessary to examine the role of these institutional venues. Institutional venues may affect social, economic and political forces as much as these forces affect institutional venues. An analysis of agenda setting and issue definition would therefore be incomplete without some examination of the importance of institutions. This is particularly important when investigating institutional venues in the EU.

It has traditionally been assumed that the EU is very receptive to the ideas of lobbyists and that these groups were capable of manipulating the EU's agenda. Accordingly, agenda setting in the EU was considered externally generated. This analysis may be valid, but it ignores the influence of the institutions of the EU. Not only do the institutions mould and even structure lobbying activities, but institutions pursue their own agendas as well. Political institutions may well 'talk up' a problem in order to see movement of that issue on to the institutional agenda in preparation for action. For example, in order to ensure the success of the White Paper on the EU's institutional agenda, Delors exaggerated the extent of economic decline in Europe. This 
would, he believed increase the chances of member state approval (Sandholtz and Zysman 1989). Furthermore, as the EU is a very open system, agenda control is made problematic. If policy advocates fail to make progress in one institutional venue, they may go 'venue shopping' and attempt to influence policy in another. The ability of policy advocates to expand the definition of a policy beyond its original confines is greatly enhanced by this openness.

The focus on the role of political institutions in shaping policy is the concern of new institutionalism, an approach that attempts to 'bring the state back in' to policy analysis. Rather than simply concentrating on the formal administrative, legal and political dimension of institutions, a characteristic of old institutionalism, new institutionalism widens the definition of an institution. Although still accommodating the formal rules, procedures and practices of institutions, new institutionalism also highlights the importance of informal arenas such as informal rules, norms, symbols, beliefs and codes of conduct. New institutionalism therefore better reflects the 'real' culture of institutions than its 'old' variant (March and Olsen 1989).

New institutionalism is useful in the study of European integration because it can help explain not only policy and institutional inertia, but also change. As such it does not represent a macro-theory attempting to scientifically map out future integration. Rather, new institutionalism attempts to re-focus methodology by bringing institutional factors back into the analysis of European integration. In essence, therefore, new institutionalism asserts that institutions matter (Armstrong and Bulmer 1998: 50). From within the broad scope of new institutionalism can be distilled two institutionalist categories relevant to the debate about policy and institutional change and inertia in the EU. The main difference between rational choice institutionalism and historical institutionalism is the emphasis they place on the deterministic effect of institutions on political outcomes.

The rational choice element in this category of new institutionalism derives from the emphasis of the importance of utility-maximising individuals with clear intentions within the policy process. The institutionalist element emphasises the importance of institutions in affecting and constraining an individual's choice within that process. Armstrong and Bulmer describe rational choice institutionalism as being at the thin end of institutionalism, as institutions and their rules only modify an essentially rational choice model of politics (Armstrong and Bulmer 1998: 53).

At the 'thicker' end of institutionalism lies historical institutionalism. Historical institutionalists ascribe a greater role for institutions within the policy process. Rather than simply constraining individual action, institutions, as defined in the broadest sense encompassing formal and informal practices, can shape and determine individual preferences. As such, historical institutionalism stresses how policy evolution is structured by prevailing institutional configurations and norms. Furthermore, institutions structure access to the political process, thus further influencing policy evolution 
(Armstrong and Bulmer 1998: 52-60). In short, institutional configurations and norms can create a governance regime capable of structuring a policy debate and hence policy development and evolution. Two studies employing an historical institutionalist analysis have added depth to our understanding of systemic and institutional agenda setting. Pierson's analysis of the development of EU social policy examines the historical development of EU institutions and how prevailing institutional norms and configurations contribute to path-dependent policy evolution (Pierson 1996). Bulmer's study of the governance of the Single European Market similarly employs an historical institutional analysis. However, rather than examining how institutional features constrain actors, Bulmer examines how prevailing institutional norms and configurations structure policy debate within the EU (Bulmer 1998).

\section{Taking an institutional (wrong) turn?}

The danger with the above approach lies in falling into the trap of placing too much distance between state and society whilst claiming to do the opposite. The actor/institutions methodology employed in this text does not simply assert that both actors and institutions matter. To do so risks bracketing off the role of actors or institutions and focusing the analysis accordingly. A methodology which does this can hardly claim to integrate both actor-based and institutions-based approaches. In other words, the actorbased and institutions-based components should closely relate to one another. Alone the ACF is unable to capture the crucial role played by the formal and informal institutional decision-making context. As such, the researcher needs to take an 'institutional turn' (Jessop 2000). However, does the reliance on new institutionalism represent an institutional wrong turn? An institutional turn refers to, 'the more or less consistent elaboration of the intuition, hypothesis, or discovery that institutions matter in one or more theoretical, empirical, or practical contexts where their existence and/or relevance had previously been overlooked, denied or ignored' (Jessop 2000: 1).

According to Jessop, academics usually take one of three institutional turns. Those taking a thematic turn simply acknowledge that institutions are important. Those taking a methodological turn may acknowledge that an institutional analysis is an essential starting point for research but in addition chose to examine other variables. Those taking an ontological turn assert that institutions 'are the primary axis of collective life and social order' (Jessop 2000: 4). Lying at the 'thicker' end of new institutionalism, historical institutionalism can be interpreted as an ontological institutional turn.

Making some kind of institutional turn is crucial to understanding task expansion in the EU. The complex multi-level structure of the EU provides opportunities for actors to exploit. Institutional design privileges one set of actors and their strategies over another. However, to take an ontological institutional turn would in effect downplay the role of key policy actors in 
the process of policy change. Although institutions affect the strategies of actors through the actor selectivity inherent in their design, actors 'have some freedom of manoeuvre more or less skilfully and reflexively to choose a path of action' (Jessop 2000: 10). This is particularly pronounced in the EU.

Consequently, the researcher needs to develop a methodology capable of recognising the importance of formal and informal institutional configurations on policy development, without over-emphasising path dependence, whilst recognising that actors in the EU possess significant room for tactical manoeuvre. Jessop's strategic relational approach (SRA) provides some guidance for those wishing to explore the role of actors in the policy process but who want to make an institutional 'turn' (Jessop 1990, 2000). Applying the SRA to the task expansion debate in the EU would involve examining how the institutional structure privileges certain actors whilst also examining how actors 'take account of this differential privileging through strategic context analysis when choosing a course of action' (Jessop 2000: 9). In other words institutional design is important but so also is how actors respond to this. Actors may for instance attempt to influence policy in venues in which they are privileged or they may adopt 'reflexive' strategies in which case they adapt in order to take advantage of the channels of access that institutions provide. In other words the methodology developed in this chapter seeks to analyse actors and institutions in terms of how they relate to each other rather than placing too much distance between them.

\section{Conclusions}

Approaches attempting to explain the process of integration (including the legal variants) struggle to capture the nature of day-to-day EU governance. As such, the analytical framework employed in this text is drawn from approaches examining the politics of governance. This methodology has been developed in three stages. First, it is important to characterise the EU as a multi-level organisation. Decision-making capabilities are shared rather than monopolised. This institutional description establishes the context within which policy change takes place. Policy evolution and change within this multi-level organisation takes place through a two-stage process, best defined by Pollack as involving the initial expansion of the EU's agenda to include new policy areas and the subsequent substantive development of these policies. As Cobb and Elder remind us, this means that an issue must first appear on the systemic agenda before being actively considered on the institutional agenda. Elite writers such Schattschneider argue that conflict can lead to agenda expansion but this expansion is controlled by elites. However, because of the multi-level nature of governance in the EU, agenda control is more problematic. The initial definition of an issue on the institutional agenda may take place with heavy definitional bias due to the venue 
within which the issue is considered. Many policy subsystems (including sport) are initially heavily influenced by legal and technocratic norms due to the constitutional predominance of negative integration. However, as Rochefort and Cobb remind us, others will be drawn into the issue definition stage in protest at the initial definition. Frequently this involves the weaker advocacy coalition attempting to re-define an issue by penetrating the subsystem with political argument. In a multi-level organisation, if they are unsuccessful in one venue they will go 'venue shopping'.

The second stage in the construction of the approach analyses the crucial role played by competing policy advocates working within policy subsystems. Although a range of actor-based approaches could be employed for the purposes of this analysis, Sabatier's Advocacy Coalition Framework sits most comfortably with the conception of EU governance employed in this study. According to Sabatier policy evolves as a result of competition between rival policy advocates. Advocates seek to steer policy in a direction consistent with their belief system. The focus on the power of ideas as opposed to the power of pressure and influence is an important contribution but alone is insufficient to fully account for the real nature of policy change in the EU. The third stage in the construction of the approach seeks to confront this 'reality'.

This third stage involves linking the strategies of key policy advocates to the prevailing institutional structure of the organisation in question. This involves taking a methodological as opposed to an ontological institutional turn. To give Sabatier's work relevance to the EU and to address the issue of how to explain coalition action, the taking of such an institutional turn is crucial. However, the finding that 'institutions matter' in the context of coalition action refers to more than just the observation that key institutions are players (actors) in the game. One should not confuse institutions with actors. To do so would negate the need to build into Sabatier's framework an institutional theory. The institutional characteristics of the EU's policy process and political system, such as the existence of a multi-layered and multi-venue EU structure, have profound effects on the dynamics of policy change. The elaboration of these characteristics is crucial if Schlager's criticism concerning the explanation for coalition action within the ACF is to be addressed. In this connection, the work of Baumgartner and Jones is important because it alerts us to the relationship between policy image and institutional venue. In 'open' political systems such as the EU, policy subsystems can be challenged by actors exploiting other institutional venues. The venue in which a policy is discussed will have a significant impact on how the policy is disposed of in terms of outputs. To add analytical depth to the work of Baumgartner and Jones, this study employs new institutionalism as an essential institutional ingredient. Institutions, defined in the widest sense, constrain and empower actors whilst also actively shaping and even determining actor strategies. As such the brand of institutionalism employed throughout 
this book has a strong actor-based component which sits at the intersection of rational choice institutionalism and historical institutionalism. Without an institutional analysis of policy change and development it becomes tempting merely to emphasise how the political agenda is pushed and pulled around by societal, economic or political forces. As such, political institutions cannot merely be seen as neutral arenas in which these forces are played out.

The interplay between actors and institutions creates policy-specific governance regimes within policy subsystems. In order to operationalise the analytical methodology, these governance regimes need identifying. This involves identifying the range of actors involved in the subsystem, identifying their prevailing belief system and calculating the institutional resources they have at their disposal. By doing so the researcher can assess the viability of coalition strategies and therefore allow for assumptions to be made concerning the future direction of policy within the subsystem. It therefore becomes clear why macro approaches have limited utility in this respect. The analytical methodology employed is not designed to be a predictive tool, it simply allows the researcher to identify possible future policy directions. The predictive quality of the approach is limited by the possibility of perturbations external to the subsystem. External perturbations cannot easily be built into the methodology. For example, the change in the economic status of sport throughout the 1990s proved crucial in forging a link between sport and EU law. A dramatic slump in the economic status of sport or a sudden (although unlikely) fall in the public's interest in sport would, for example, limit the political salience of the issue.

Although governance regimes differ between policy subsystems, they are likely to share certain systemic qualities. First, they are influenced by the constitutional structure of the EU. Treaties not only determine the institutional balance of power within subsystems, they also shape the working logic of integration. For example, embedded within the Treaty of Rome is a commitment to advance both economic integration and socio-cultural/political integration. Such a commitment has resulted in the emergence of competing advocacy coalitions seeking to direct policy in either a market-based or socially based direction. The institutional balance between these advocacy coalitions varies according to institutional power. As Pinder remarked observing the EU in the 1960s, the 'free trade ideology is firmly built into the system, but the planning ethic is no more than a possibility for the future' (Pinder 1968: 98). Since then, the institutional balance has shifted. The Parliament has for example acquired enhanced powers over legislation and the budget. Furthermore, the Single Market has been completed and since Maastricht the planning ethic is more deeply ingrained. Accordingly, sociopolitical arguments advanced by advocacy coalition's within subsystems previously dominated by legal and technocratic norms have strengthened over time. 
Second, they are likely to be influenced by ECJ jurisprudence and the quasi-judicial role played by the Competition Policy Directorate. In particular, Court rulings frequently establish important legal principles guiding the development of policy. In this connection, it is possible to identify a relationship between judicial and legislative/policy processes. However, just as policy initiatives are influenced by judicial or quasi-judicial actions, so the activities of the ECJ and Commission can be influenced by political activity.

Third, governance regimes are likely to be influenced by soft law. Political declarations of intent, although not legally binding, do shape policy evolution and do provide institutional actors with some guidance. In addition, the office of Council Presidency allows member states to push individual agendas. Continuity is ensured by the troika system but agendas can expand as the incumbent continues the predecessor's agenda whilst also developing their own.

Fourth, deeply ingrained within the EU's general approach to policy development is a desire to mediate between conflicting positions. This reflects the complex multi-dimensional and multi-national nature of EU decision making. Through a learning process over time, the EU has developed a range of mediating tools and practises. As Sabatier reminds us, 'in situations in which all major coalitions view a continuation of the current situation as unacceptable, they may be willing to enter negotiations in the hope of finding a compromise that is viewed by everyone as superior to the status quo' (Sabatier 1998: 119). However, mediation will only take place where competing advocacy coalitions are relatively evenly matched or the activities of one coalition do not directly pose a threat to the deep and policy core belief system of the rival coalition. If an advocacy coalition has monopolistic or near monopolistic control over policy evolution, it is unlikely they will mediate. In situations where one coalition is institutionally underprivileged mediation is unlikely unless that coalition can form a coalition of convenience with other groups. Where two coalitions seek to influence policy through a variety of tactics and institutional venues, policy coherence is lost. Under such circumstances policy brokers will seek to mediate between coalitions.

Finally, governance regimes are likely to be influenced by major developments both internal and external to the subsystem. A change in the institutional balance of power prompted by a Treaty change has the potential to fundamentally alter the institutional resources available to actors. External changes also affect subsystems. For example, the collapse of communism greatly affected the content and timing of the Maastricht Treaty. Similarly, the Danish rejection of Maastricht in a referendum affected the nature of the subsequent Amsterdam Treaty. Both Treaties fundamentally altered the balance of power within numerous policy subsystems.

On the face of it the above framework appears disproportionately oversize in order to explain the apparently straightforward question of why EU 
policy towards sport has changed? However, the shifting focus of regulatory attention away from a Single Market model of sports regulation towards a socio-cultural model raises many complex issues concerning the dynamics of policy change in the EU. In particular, in the absence of a specific legislative framework for sport, the interplay between the formal arena of law and the informal arena of political pressure and conflicting value systems becomes an important focus for analysis. How does theory capture this interplay? This is a far more complex question. The remaining chapters of the text analyse the shifting focus of EU sports policy in light of these theoretical insights. The next chapter analyses the composition of the sports policy subsystem - an essential methodological starting point for understanding sports policy change in the EU.

\section{Note}

1 The four freedoms are the free movement of goods, services, labour and capital. 